\title{
Resources
}

Teaching Oceania: Creating Pedagogical Resources

for Undergraduates in Pacific Studies

MONICA C LABRIOLA AND JULIANNE WALSH

The Contemporary Pacific, Volume 32, Number I, I73-I85

(C) 2020 by University of Hawai' $i$ Press 


\section{Teaching Oceania: Creating Pedagogical \\ Resources for Undergraduates \\ in Pacific Studies}

Monica C LaBriola

and Julianne Walsh

Learning is a process, not a product that ever comes to us whole or complete.

- Teresia Teaiwa, “The Classroom as a Metaphorical Canoe"

The late Teresia Teaiwa articulated a vision of Pacific studies education as a "journey of cooperative learning towards alternative spaces where indigenous knowledges can be more fully reclaimed, affirmed, and revitalized" $(2005,48) .{ }^{1}$ To help navigate this journey, Teaiwa encouraged teacher-scholars to re-vision their Pacific studies classrooms as metaphorical canoes and themselves as navigators whose primary role is to provide the resources, tools, and skills students need to succeed in the classroom and beyond. Recognizing that no one person can be an authority on the entirety of the vast Pacific region, Teaiwa called on Pacific studies faculty to seek out collaborative pedagogical approaches and to share knowledge, methods, content, and media across disciplinary and geographical areas of expertise. These and other efforts, she proposed, contribute to the transformation of classrooms into vessels for cooperative, interactive learning and student empowerment in and across Oceania's "immensity and diversity" $(2005,38)$.

In 20I6, the University of Hawai'i (UH) at Mānoa Center for Pacific Islands Studies (CPIS) took a step toward realizing this vision of cooperative education in alternative spaces by bringing together twenty-five scholar-

The Contemporary Pacific, Volume 32, Number I, I74-I85

(C) 2020 by University of Hawai'i Press 
educators from twelve college campuses in the United States, the Pacific Islands, and Japan to share their knowledge and expertise in the production of the first volumes of CPIS's new Teaching Oceania series. ${ }^{2}$ Spearheaded by Julianne Walsh and funded by CPIs's federal National Resource Center (NRC) grant-and with additional support from Kapi'olani Community College and Brigham Young University-Hawai' $i$ - the three-day Teaching Oceania workshop aimed to produce four multiauthored, interactive, digital teaching units for undergraduate students in Pacific studies. The proposed minitextbooks would use an interdisciplinary, regional approach to broadly introduce themes relevant to Pacific studies and the Pacific Islands region more generally. Working in groups of five to six, the scholars brought their disciplinary, content, and geographical expertise to the table to collectively conceptualize and draft the books, which would become the first volumes of the series. After the conclusion of the threeday workshop, a team of editors and designers crafted the drafts into digital, interactive, open-access iBooks (updated and also made available as EPUBs, another e-book file format, in 2018), complete with student learning outcomes; activities; interactive maps and images; embedded videos, spotlights on Indigenous activists, practitioners, and scholars; and other innovative features. CPIS used NRC funds to host the initial workshop, including travel and lodging for many of the participants, and to pay for the editing, design, and layout of the finished volumes. ScholarSpace, UH Mānoa's digital institutional repository, was designated to host the books and make them freely available to students, teachers, and the general public. After months of intensive planning and coordination by Walsh, Mary Hattori, Terence Wesley-Smith, Michelle Noe Tupou, Iwalani Koide, and Hiagi Wesley, the workshop groups embarked on an intensive creative journey that demonstrated the power and possibilities of cooperation and collaboration not just for our teaching and scholarship but also for our own journeys of learning in and through Pacific studies. Since the initial workshops, guest editors, authors, and contributors have used online collaborations and designated sessions at academic conferences and workshops to draft subsequent volumes.

\section{Conception and Development}

The Teaching Oceania workshop and digital publication series of the same name were the culmination of several years of seeking out, envisioning, and testing pedagogical resources for undergraduates pursuing Pacific 
Islands studies (PACS) courses at UH Mānoa and across the ten-campus UH system. In the decade since the first introductory PACs courses were offered at UH Mānoa and Kapi'olani Community College, faculty had been struggling to locate appropriate resources for undergraduate students, whose reasons for pursuing Pacific Islands studies ranged from wanting to learn more about their heritage to fulfilling university graduation requirements. Since 20IO, UH campuses had seen a dramatic increase in the number of students pursuing Pacific Islands studies, with several sections of the introductory PACS IO8 course offered every semester both in person and online at UH Mānoa and UH West O'ahu, at various community colleges, and through college-ready programs for high school students and incoming freshmen such as the Hawai'i Undergraduate Initiative and Pasifika Passion Pipeline. Beyond Hawai'i, undergraduate students were enrolling in similar introductory courses at institutions across the region and on the US continent, such as Victoria University of Wellington in Aotearoa New Zealand, the Fiji-based University of the South Pacific (which includes campuses throughout the region), the Australian National University, American Samoa Community College, and City College of San Francisco. To successfully engage these diverse students, including Pacific Islanders raised in the region or the diaspora and others with little to no previous experience with Pacific cultures or histories, Pacific studies programs and faculty had to devise innovative teaching methods and locate level-appropriate resources. These digital pedagogical tools and materials needed not only to convey Pacific studies content but also to offer students skills and strategies to critically engage with the most significant issues faced by Pacific communities today.

For Pacific studies programs and faculty who until the early 2000 s were focused on working with graduate students and producing their own scholarship, new undergraduate courses and programs represented a major departure. For its part, CPIs had offered a master of arts (MA) degree exclusively for six decades—adding a graduate certificate in Pacific Islands studies in 1979-and faculty were accustomed to working closely with relatively small groups of graduate students in the classroom, advising individual students working on their MA theses or portfolio projects, and serving on dissertation committees for doctoral candidates in other departments. In 2010, CPIs launched a bachelor of arts (BA) degree in Pacific Islands studies and expanded its undergraduate course offerings to meet student demand and the requirements of this new degree. The shift was historic for CPIS and dramatic for faculty, who at the time had 
little or no experience teaching undergraduates in general and those in their first and second years of college in particular. As faculty reenvisioned their teaching strategies and searched for materials to use in undergraduate classrooms, the overall dearth of resources appropriate for students at that level quickly became apparent. At the same time, student course evaluations and conversations with students revealed that faculty were assigning excessive amounts of reading and that course materials were frequently too advanced and not always entirely relevant to course topics or themes. The gap between course requirements and student preparedness was not due to lack of effort or awareness on the part of faculty, who experimented with compiling course packets and readers, assigning book chapters and partial texts, and supplementing primary and other sources with class lectures. Some used existing textbooks to introduce undergraduates to the Pacific Islands, but these proved either too advanced or too basic, and none reflected the hallmark interdisciplinarity of Pacific studies (Wesley-Smith 1995; Hviding 2003; Whimp 2008).

As CPIS curriculum specialist and undergraduate advisor, Walsh took these findings and feedback seriously and in $20 \mathrm{I} 2$ launched a project aimed at locating teaching resources for undergraduates and making them available to Pacific studies faculty in Hawai'i and beyond. The result was the Pacific Islands Studies Wiki compiled by CPIS Graduate Assistant Kelea Levy and shared with members of the UH systemwide PACs working group. Designed primarily for Pacific studies instructors, the wiki brought together online content that could enhance such key PACs IO8 topics as geography, origin stories, colonization, development, migration and diaspora, and the environment. While the wiki was intended to help instructors discuss and share undergraduate-level resources, it soon became clear that in order to be accessible to the students who needed them most, these resources would have to be more structured and user-friendly. Hoping to address this deficiency, Walsh and Levy began to envision how they might not only identify existing resources but actually create new materials and make them available to instructors and students beyond CPIs. To be an effective tool for undergraduate learning in Pacific studies, these resources would need to scale back advanced academic discourse and jargon and use language that is accessible, engaging, and meaningful for an untried undergraduate audience. To captivate students who typically spend more time on social media than reading textbooks and academic journal articles, they would also need to be visually appealing and include a variety of interactive, "click-worthy" features (Wesch 2007). 
At roughly the same time that Walsh and Levy were exploring new ways to use digital media to engage with undergraduate students, UH Mānoa was beginning to embrace the global open access movement. ScholarSpace and eVols, the University of Hawai'i's digital repositories, were established in 2008 , with CPIS being an early adopter. Today, all but the most recent volumes of The Contemporary Pacific and a vast array of other CPIS publications and student work are freely available for download via ScholarSpace. In 20ı, the Mānoa Faculty Senate adopted a resolution on open access created by a faculty-led scholarly communication committee. This new policy was enacted in $20 \mathrm{I} 2$ by the university's Office of the Vice Chancellor for Academic Affairs and, as noted in its statement of purpose, was developed in part to "[ensure] access to scholarship that is digital, free of charge to the user, free of most copyright restrictions, and is disseminated over the Internet" (OVCAA 2OI 2, I).

Following the 2013 CPIS conference "Waves of Change: Climate Change in the Pacific Islands and Implications for Hawai'i," Walsh and Levy began experimenting with the Apple application iBooks Author to create a sample minitextbook built around the PowerPoint slides and notes CPIS faculty were using to teach PACS I08. The result was not a text-centered e-book but rather an interactive multimedia introduction to a unit on climate change in the Pacific Islands that incorporated text, images, video, links to outside resources, and other interactive features. The mockup showed how Pacific studies content could be crafted into dynamic, graphically engaging multimedia units that appeal to contemporary undergraduate students-and the idea for the Teaching Oceania series was born.

In Spring of 20I 5 , two of Walsh's PACs 4 OI (senior capstone) students accepted the challenge to create a digital language resource as their final project. Teora Morris and Andrea Staley organized a small Tahitian language learning community with the support of UH Mānoa Tahitian language instructor Steve Chailloux. Their work with the community resulted in an introductory iBook for children learning Tahitian. Both Morris and Staley excelled in learning iBooks Author and exploring its features. Ultimately, they were the experts at CPIS whose design and implementation work resulted in producing the first digital texts of the series.

\section{From Workshop to SERIES}

Inspired by the iBook demo, CPIS requested federal NRC grant funds to support a collaborative Teaching Oceania workshop aimed at creating 
interdisciplinary and thematic digital minitextbooks appropriate for undergraduates or anyone with an interest in the Pacific Islands. The first four volumes were drafted at the initial 2016 workshop and later published as Teaching Oceania volumes I-4 (table I). For two days and over several working sessions, groups of teacher-scholars gathered around tables to compose the texts collaboratively using Google Docs. While each group had its own approach to drafting-some divvied up sections for individual contributors to write, while others distributed among group members such tasks as generating text, locating multimedia, and producing content for sidebars and interactive widgets-the end result was four initial drafts ranging from fifteen to twenty-five single-spaced pages of text on the assigned topics.

At the conclusion of the workshop, the conveners asked each group to select one or two members to be post-workshop liaisons who would continue to work on the drafts by filling in any gaps in the text, creating rel-

TABLE I Current and Forthcoming Teaching Oceania Volumes

\begin{tabular}{|c|c|c|c|}
\hline $\begin{array}{l}\text { Year of } \\
\text { Publication }\end{array}$ & Volume & Title & Authors \\
\hline $\begin{array}{l}2016 \text { (updated } \\
\text { in } 2018 \text { ) }\end{array}$ & I & $\begin{array}{l}\text { Militarism and } \\
\text { Nuclear Testing } \\
\text { in the Pacific }\end{array}$ & $\begin{array}{l}\text { Joseph H Genz, Noelani Goodyear-Ka‘ōpua, } \\
\text { Monica C LaBriola, Alexander Mawyer, } \\
\text { Elicita N Morei, and John P Rosa }\end{array}$ \\
\hline $\begin{array}{l}2016 \text { (updated } \\
\text { in } 2018 \text { ) }\end{array}$ & 2 & $\begin{array}{l}\text { Gender in the } \\
\text { Pacific }\end{array}$ & $\begin{array}{l}\text { Greg Dvorak, Delihna Ehmes, Evile Feleti, } \\
\text { Tēvita O Ka'ili, James Perez Viernes, } \\
\text { and Teresia Teaiwa }\end{array}$ \\
\hline $\begin{array}{l}2017 \text { (updated } \\
\text { in } 2018 \text { ) }\end{array}$ & 3 & $\begin{array}{l}\text { Health and } \\
\text { Environment } \\
\text { in the Pacific }\end{array}$ & $\begin{array}{l}\text { Tarcisius Kabutaulaka, Jacki Leota-Ete, } \\
\text { Kealalōkahi Losch, Fleur Enchante Palmer, } \\
\text { Damon Salesa, Hiagi Wesley, Terence Wesley- } \\
\text { Smith, Sarah Wongking }\end{array}$ \\
\hline 2019 & 4 & $\begin{array}{l}\text { Oceanic Arts: } \\
\text { Continuity and } \\
\text { Innovation }\end{array}$ & $\begin{array}{l}\text { Katherine Higgins, Ingrid Ahlgren, Jesi Lujan } \\
\text { Bennett, Mariquita Micki Davis, Emelihter } \\
\text { Kihleng, Te Raukura Roa }\end{array}$ \\
\hline 2019 & 5 & $\begin{array}{l}\text { French Speaking } \\
\text { Islands of } \\
\text { Oceania }\end{array}$ & $\begin{array}{l}\text { Alexander Mawyer, Terava Ka'anapu Casey, } \\
\text { William Matt Cavert, Lorenz Gonschor, Teora } \\
\text { Morris, Sylvie Largeaud-Ortéga, Louis Bousquet, } \\
\text { Patrice Godin, Mirose Paia, Titaua Porcher, } \\
\text { Bernard Rigo, Bruno Saura, Virginie Soula, } \\
\text { Serge Tcherkézoff, Jacques Vernaudon }\end{array}$ \\
\hline
\end{tabular}


evant activities or assignments to be interspersed throughout, and approving images and videos to embed in the final publication. At that time, CPIS also brought on board Monica C LaBriola as series editor. LaBriola's primary task was to work with Walsh and other CPIS faculty and staff to revise and rework compiled drafts of the first five volumes for consistency in style and voice and to ensure the content is presented in language that is appropriate and engaging for undergraduates. Under Walsh's supervision, CPIS graduate assistant Andrea Staley and future CPIS MA student Teora Morris took the lead in designing the initial volumes, with Staley primarily responsible for the first volume and Morris responsible for the subsequent four. Walsh coordinated edits, images, and layout with all involved. CPIS faculty member Alexander Mawyer helped locate images and media, and then CPIS managing editor Jan Rensel did the final copyediting for the first three volumes, which were made available for free download worldwide via ScholarSpace within several months of the initial workshop.

Since the 2016 workshop, the Teaching Oceania series has developed into a set of digital minitextbook units designed to advance Pacific studies pedagogy at the undergraduate level. Interactive features such as embedded video, audio, and slideshows are included in the iBook and EPUв versions. To increase availability to users with limited access to the Internet, which can make downloading large applications and files difficult, all volumes can also be downloaded from ScholarSpace as noninteractive PDFs, at a much-reduced file size. As of this writing, volume 4, Oceanic Arts: Continuity and Innovation, has been reworked and will soon be published in iBook, ЕPUB, and PDF formats.

In April 20I8, LaBriola began promoting the series to Pacific studies faculty at relevant academic conferences, including those organized by the Australian Association of Pacific Studies, the Pacific History Association, and the European Society for Oceanists. Also in 2018, LaBriola launched the Teaching Oceania Series Facebook page, and CPIS graduate assistant Patricia Tupou started advertising the series and other undergraduate resources on Twitter. Together, the conference presentations and social media presence have dramatically expanded the series's reach and accessibility, making it easier for the Teaching Oceania team to promote new volumes, announce updates, and share undergraduate teaching resources across the region and globally. In conjunction with the original 2016 workshop, UH Mānoa Library Pacific Collection Librarian Stuart Dawrs established a "Teaching Oceania: Open Access Resources” library 
guide, which includes many of the links and resources featured in the Teaching Oceania volumes, along with links to other freely available online resources.

By September 2019, the first three volumes of the Teaching Oceania series had been downloaded from ScholarSpace more than I I,700 times by users in the Pacific Islands, the United States, Australia, Asia, and Europe, and the Teaching Oceania series Facebook page had more than 380 likes and followers. From 9 July through the end of August 2018, Facebook posts announcing the revised editions and new EPUBs organically reached almost ten thousand people worldwide. These numbers demonstrate the effectiveness of online repositories and social media platforms for distributing and promoting these digital resources.

\section{Current and Future Volumes}

Grounded in Indigenous voices, cultures, and perspectives, the Teaching Oceania series provides an overview of topics relevant to Pacific studies and the Pacific region. While ideal for students in introductory Pacific studies courses, the volumes complement other college courses in anthropology, geography, history, ethnic studies, gender studies, and political science. Similar to a Pacific studies survey course, each volume is organized around a central theme or unit and applies a regional, interdisciplinary lens to present the topic from diverse perspectives and approaches. Following Walsh's original conception, these are level-appropriate texts that appeal to modern-day students who not only are well-versed in a variety of digital platforms but also have come to expect learning materials that are affordable and readily accessible. The units are visually appealing and interactive, each with dozens of expandable images, informative scroll boxes, embedded video and audio components, glossary entries with popout definitions, links to outside resources, and other features. Each volume also includes clearly stated student learning outcomes and activities or discussion questions that students can work on independently or with classmates as they move through the unit. The following is a brief overview of existing and upcoming volumes, as well as the editors' plans for developing the series further.

Volume I, Militarism and Nuclear Testing in the Pacific, seeks to prompt critical thinking and instill in readers empathy with Pacific Islanders whose lives have become inextricably intertwined with the histories, 
legacies, lived realities, and uncertain futures wrought by militarism and nuclear testing in the region. Student learning outcomes include mapping militarism and nuclear testing in the Pacific Islands, discussing the impacts of militarization and nuclear testing on Pacific communities and environments, and reflecting on Indigenous and local responses and resistance to militarization and nuclear testing. Volume 2, Gender in the Pacific, introduces diverse gender identities and roles and illustrates some of the ways these are shaped by culture, place, and encounters with other peoples and societies. The unit gives students the capacity to describe how patrilineal and matrilineal descent inform and shape gender roles across the region, to explain the role of gender in the division of labor, to distinguish between biological sex and gender identity and how these concepts overlap and differ across cultures and societies, to exhibit an understanding of thirdgender identities in Pacific contexts, and to articulate how cross-cultural encounters have impacted gender roles and constructs.

Volume 3, Health and Environment in the Pacific, asks students to think about relationships between the environment and individual and collective health and well-being, along with the impacts of environmental and health issues on Pacific Islanders and how these can be addressed today and in the future. The unit provides tools for students to identify environmental and health challenges in the Pacific Islands, to describe diverse Pacific Islander cultural perspectives about the environment and health, and to explain effective individual and collective approaches to addressing environmental and health challenges in the region. Volume 4, Oceanic Arts: Continuity and Innovation, introduces art and artistic practice in the Pacific Islands across time and space, emphasizing Indigenous worldviews and creative practices and interpretations informed by artists' personal experiences, aesthetic values, and social, cultural, and environmental contexts. The unit prompts students to describe key themes, issues, and concepts in Oceanic art, to discuss the origins and development of one or more types of Oceanic art, to analyze Oceanic art using Indigenous and interdisciplinary perspectives, and to reflect on how personal and cultural identities, cultural continuity and change, and social transformation are reflected in and by artistic expression(s).

Scholars from Université de la Polynésie Française, Université de la Nouvelle-Calédonie, and uH Mānoa, among others, have authored a volume on France in Oceania, produced as part of their triannual gathering, "Oceania Ensemble," held at UH Mānoa in November 20I8. This volume, French Speaking Islands of Oceania (volume 5), explores such key 
issues in the French-speaking Pacific as language, colonialism, sovereignty, nuclear legacies, arts and literature, identity and indigeneity, and the environment. Options are also being explored for translating the volume into French, as well as possibilities for future collaborations and translations of existing units.

As of this writing, plans are underway to produce additional Teaching Oceania volumes. In March 20I9, CPIs hosted a workshop titled "Envisioning Pacific Islands and Oceania Studies in the US and Beyond." While a primary goal of the workshop was to consider the steps necessary to form a US-based Pacific Islands Studies Professional Association, workshop participants also devoted one day of the gathering to collaborating on a manuscript titled "An Introduction to Pacific Islands Studies" as yet another installment in the Teaching Oceania series.

CPIS has procured funding with the goal of producing up to four more digital units. Potential topics for the next phase include: migration and diaspora, orality and literature, leadership and governance, land issues, and decolonization and sovereignty movements, among others. While the process for drafting these texts might mirror the original workshop format, CPIs hopes to enhance the infrastructure of the Teaching Oceania publication series by forming a full editorial board, institutionalizing a graduate assistantship, and hiring professional designers to manage the layout of future editions. Until then, proposals for guest-edited volumes are welcome, and the series will continue to follow submission and editing processes similar to those used by this journal. Full details can be found on CPIS's Teaching Oceania web page. Announcements of new or revised volumes will continue to be shared via Facebook, Twitter, and other social media platforms (using the hashtag \#teachingoceania) as they become available.

\section{Notes}

I The University of Hawai'i system refers to the field as "Pacific Islands studies," while other regional institutions use "Pacific studies," among other terms. For the purposes of this paper, we use "Pacific studies" when referring broadly to the academic discipline and "Pacific Islands studies" when referring specifically to courses and named initiatives at the University of Hawai'i.

2 The URLs for the Teaching Oceania series and other websites and online resources mentioned in this essay are listed in appendix I. 


\section{References}

Hviding, Edvard

2003 Between Knowledges: Pacific Studies and Academic Disciplines. The Contemporary Pacific I 5 (I): 43-73.

ovcAa, Office of the Vice Chancellor for Academic Affairs, University of Hawai'iMānoa

2012 Open Access Policy. Memorandum, 4 April. https://manoa.hawaii .edu/ovcaa/admin_memos/pdf/memo_040420I2_openaccess.pdf [accessed I9 June 20I9]

Shigematsu, Setsu, and Keith L Camacho, editors

2010 Militarized Currents: Toward a Decolonized Future in Asia and the Pacific. Minneapolis: University of Minnesota Press.

Teaiwa, Teresia

2005 The Classroom as a Metaphorical Canoe: Co-operative Learning in Pacific Studies. World Indigenous Nations Higher Education Con-

Wesch, Michael sortium Journal I:38-48.

2007 A Vision of Students Today. YouTube video, 4:44 min. Posted I 2 October. http://www.youtube.com/watch?v=dGCJ46vyR9o [accessed I9 June 20I9]

Wesley-Smith, Terence

I995 Rethinking Pacific Islands Studies. Pacific Studies I 8 (2): I I 5-I 37.

Whimp, Graeme

2008 Interdisciplinarity and Pacific Studies: Roots and Routes. The Contemporary Pacific 20 (2): 397-342.

\section{Abstract}

Teaching Oceania is a free digital textbook series produced by the University of Hawai'i at Mānoa Center for Pacific Islands Studies with the support of the US Department of Education through a Title VI grant for area studies. This article describes the initial goals, target audiences, collaborative writing, and gradual development of the series for US and regional institutions teaching interdisciplinary Pacific studies courses to undergraduate students.

KEYWORDS: Pacific studies, undergraduate pedagogy, digital resources, regionalism, teaching, Oceania 


\section{Appendix I Websites and Online Resources Mentioned}

\begin{tabular}{|c|c|c|}
\hline Website & Host & URL \\
\hline $\begin{array}{l}\text { Center for Pacific } \\
\text { Islands Studies } \\
\text { ScholarSpace } \\
\text { Community }\end{array}$ & $\begin{array}{l}\text { UH Mānoa Hamilton } \\
\text { Library }\end{array}$ & $\begin{array}{l}\text { https://scholarspace.manoa.hawaii.edu/ } \\
\text { handle/IOI } 25 / 2825\end{array}$ \\
\hline eVols & $\begin{array}{l}\text { UH Mānoa Hamilton } \\
\text { Library }\end{array}$ & https://evols.library.manoa.hawaii.edu/ \\
\hline $\begin{array}{l}\text { Hawai'i Under- } \\
\text { graduate Initiative }\end{array}$ & $\begin{array}{l}\text { UH Mānoa Office of } \\
\text { Multicultural Student } \\
\text { Services }\end{array}$ & http://www.manoa.hawaii.edu/omsshui/ \\
\hline $\begin{array}{l}\text { Pacific Islands } \\
\text { Studies Wiki }\end{array}$ & $\begin{array}{l}\text { UH Mānoa Center for } \\
\text { Pacific Islands Studies }\end{array}$ & $\begin{array}{l}\text { http://pacificstudies.pbworks.com/w/page/ } \\
59034340 / \text { Welcome! }\end{array}$ \\
\hline $\begin{array}{l}\text { Pasefika Passion } \\
\text { Pipeline }\end{array}$ & $\begin{array}{l}\text { UH Mānoa Office of } \\
\text { Multicultural Student } \\
\text { Services and Office of } \\
\text { Vice President for } \\
\text { University of Hawai'i } \\
\text { Community Colleges }\end{array}$ & https://manoa.hawaii.edu/omsspasefika/ \\
\hline ScholarSpace & $\begin{array}{l}\text { UH Mānoa Hamilton } \\
\text { Library }\end{array}$ & https://scholarspace.manoa.hawaii.edu/ \\
\hline $\begin{array}{l}\text { Teaching Oceania: } \\
\text { Open Access } \\
\text { Resources }\end{array}$ & $\begin{array}{l}\text { UH Mānoa Hamilton } \\
\text { Library }\end{array}$ & $\begin{array}{l}\text { https://guides.library.manoa.hawaii.edu/ } \\
\text { teaching_oceania }\end{array}$ \\
\hline $\begin{array}{l}\text { Teaching Oceania } \\
\text { Series ScholarSpace } \\
\text { Collection }\end{array}$ & $\begin{array}{l}\text { UH Mānoa Hamilton } \\
\text { Library }\end{array}$ & $\begin{array}{l}\text { https://scholarspace.manoa.hawaii.edu/ } \\
\text { handle/IOI } 25 / 42426\end{array}$ \\
\hline $\begin{array}{l}\text { Teaching Oceania } \\
\text { Series Facebook } \\
\text { Page }\end{array}$ & Facebook & https://facebook.com/TeachingOceania \\
\hline $\begin{array}{l}\text { Teaching Oceania } \\
\text { Series } \\
\text { Twitter Account }\end{array}$ & Twitter & https://twitter.com/OceaniaTeaching \\
\hline $\begin{array}{l}\text { Teaching Oceania } \\
\text { Series } \\
\text { Web Page }\end{array}$ & $\begin{array}{l}\text { Center for } \\
\text { Pacific Islands } \\
\text { Studies }\end{array}$ & $\begin{array}{l}\text { https://hawaii.edu/cpis/research-and } \\
\text {-publications/teaching-oceania/ }\end{array}$ \\
\hline
\end{tabular}

